\title{
A EXPERIÊNCIA DO NÚCLEO DE BAIRRO DO PROGRAMA UNIVERSIDADE ABERTA À TERCEIRA IDADE DA UNIVERSIDADE ESTADUAL DE FEIRA DE SANTANA - BA: um exercício de cidadania e solidariedade
}

\author{
Maria Geralda Gomes Aguiar* \\ Eliab Barbosa Gomes* \\ Cacilda Miranda da Silva** \\ Ana Rita Santos Pereira*** \\ Sonia Maria Freitas Cerqueira*** \\ Josélia Costa do Nascimento ${ }^{* * * * *}$
}

\section{Resumo}

Relato de experiência da intervenção sociocultural no bairro Coronel José Pinto na cidade de Feira de Santana - BA, desenvolvida por dezessete alunas do Programa Universidade Aberta à Terceira Idade da Universidade Estadual de Feira de Santana (UATI/UEFS). Trata-se de uma estratégia alternativa de ampliação das ações da UATI utilizando-se do potencial das alunas como multiplicadoras para fazer um levantamento sistemático de dados sobre o perfil socioeconômico e cultural de 603 idosos residentes no bairro. Essa iniciativa, sob orientação do Núcleo de Estudos e Pesquisas da Terceira Idade (NEPTI), tem como eixo norteador a concepção de educação ao longo toda a vida, na perspectiva de delinear pautas sociais e culturais de ação solidária que possibilitem o resgate da consciência social dos idosos na luta pelo reconhecimento de direitos sociais, de sua autonomia, capacidade de integração e participação na sociedade. Constitui-se assim, em um projeto

* Enfermeira. Professora Adjunto do Departamento de Saúde da Universidade Estadual de Feira de Santana (UEFS). Membro do Núcleo de Estudos e Pesquisas da Terceira Idade (NEPTI). Doutora em Educação pela Faculdade de Educação da Universidade Federal da Bahia.E-mail: geaguiar@uefs.br

** Sociólogo. Professor Assistente do Departamento de Ciências Humanas e Filosofia da UEFS. Membro do NEPTI. Mestre em Sociologia pela Universidade Federal de Pernambuco.

*** Administradora. Membro da Equipe Técnica da Universidade Aberta à Terceira Idade (UATI) e do NEPTI.

**** Historiadora. Membro da Equipe Técnica da UATI e do NEPTI.

${ }^{* * * * *}$ Pedagoga. Coordenadora de Extensão de Projetos Especiais da Pró-Reitoria de Extensão e Cultura da UEFS. Membro do NEPTI.

${ }^{* * * * * *}$ Enfermeira. Professora Titular do Departamento de Saúde da UEFS. Membro do NEPTI. 
de revalorização do bairro que integra a ação solidária e cidadã das alunas/ idosos da UATI e dos idosos residentes no bairro, tendo como resultante das ações empreendidas a criação do Grupo de Convivência Viver Feliz. Palavras-chave: Terceira Idade. Cidadania. Solidariedade. Participação Social.

1 A Criação de Comissões de Idosos: uma estratégia para o exercício da cidadania

A Universidade Aberta à Terceira Idade (UATI) é um Programa da Universidade Estadual de Feira de Santana, criado em 1992, através da PróReitoria de Extensão e Cultura (PROEC), visando à integração do idoso no contexto universitário, ao propiciar-lhe um espaço de educação e de participação social na ótica da construção da cidadania, da produção de cultura e do lazer.

Em consonância com os objetivos do Programa Universidade Aberta à Terceira Idade de incentivar o exercício consciente da cidadania, bem como a reinserção do idoso na comunidade, criou-se a Comissão de Núcleo de Bairro. Essa iniciativa faz parte de um projeto mais amplo que consiste na busca de formas alternativas para o atendimento de demandas da expressiva população de terceira idade de Feira de Santana. Por acreditar que o reconhecimento do saber de experiência ${ }^{1}$ (DAMASCENO, 1999) é condição sine qua non para o enriquecimento e valorização de suas alunas, a UATI criou com estas, Comissões visando ampliar suas ações (UNIVERSIDADE ESTADUAL DE FEIRA DE SANTANA, 1999). Neste sentido, foram sistematizadas seis comissões: Apoio Técnico Administrativo, Núcleo de Bairro, Eventos, Relações Públicas, Assistência Social, Turismo e Lazer.

Cremos que a noção de saber de experiência é bastante apropriada para dar conta de um saber de si, de um conhecimento singular do cotidiano que as idosas constroem na sua experiência de envelhecer que ultrapassa os limites da trajetória de vida pessoal, na medida em que encontra eco em

\footnotetext{
Para Tardiff e Ouellet (1993) citados por Damasceno (1999, p. 18) o professor é um agente produtor de saberes, cujo núcleo é o seu saber de experiência. Segundo Terrien (1993) citado pela autora "[ . . . ] o saber de experiência do professor se identifica com o saber social resultante de sua práxis cotidiana." Para mais detalhes ver: TARDIF, Maurice; OUELLET, Yolande. Les savoirs professionnels et d'expérience des enseignants de métier. Québec: Université Laval, 1993 e THERRIEN, Jacques. O Saber Social da Prática Docente. Educação e Sociedade, Campinas, n. 46, p. 408-418, 1993.
} 
relatos de outros idosos e também com alguns dos temas de estudiosos do envelhecimento.

A Equipe Técnica do Programa Universidade Aberta à Terceira Idade (UATI) tomou como base de suas ações a estratégia das alunas como agentes multiplicadoras. Partiu então, da premissa de que essas atuariam como facilitadoras ao assumirem a coordenação das propostas de intervenção no bairro, sendo, portanto, ativistas do que podemos definir como práticas voluntárias. Esta estratégia encontra apoio também nos pilares para a educação no século XXI, estabelecidos pelo Relatório Edgar Faure para a UNESCO em 1972, destacadamente, aprender a conhecer e aprender a fazer (DELORS, 1999).

Aprender a conhecer implica " $[$. . . ] conciliar uma cultura geral suficientemente vasta, com a possibilidade de dominar profundamente, um reduzido número de assuntos $[\ldots] . "$

A cultura geral é o elemento capaz de propiciar as condições para uma educação permanente, pois fornece as bases para que a aprendizagem se dê ao longo de toda a vida. Já o aprender a fazer, é concebido com um imperativo da aprendizagem para a aquisição de " [... ] uma competência mais ampla que prepare o indivíduo para enfrentar numerosas situações, muitas delas imprevisíveis, e que facilite o trabalho em equipe." (DELORS, 1999, p. 20).

As diretrizes do Programa Universidade Aberta à Terceira Idade encontram-se em consonância com o conceito de educação ao logo de toda a vida, que conforme Jacques Delors (1999) é uma das chaves de acesso ao século XXI. Parte-se do entendimento da educação como um processo contínuo de construção da pessoa humana, dos seus saberes e aptidões, da sua capacidade de tomar decisões. $O$ conceito de educação permanente, presente já no Relatório Edgar Faure, publicado pela UNESCO em 1972 foi retomado e atualizado pela Comissão Internacional sobre Educação para o século XXI "[ . . . ] de modo a conciliar a competição que estimula, a cooperação que reforça e a solidariedade que une [ . . . ].” (DELORS, 1999, p. 15).

Nossa intenção com a criação das Comissões foi possibilitar experiências de intervenção no tecido social que ultrapassassem os limites das Oficinas de Corpo e Socioeducativas em si, como atividades formais das alunas na UATI. Esta iniciativa tem como eixo norteador o delineamento de pautas sociais e culturais de ação cidadã e solidária, que propiciem o despertar 
da consciência das idosas na luta pelo reconhecimento de direitos sociais, de sua autonomia, da capacidade de integração e de participação na vida do bairro. É interessante destacar sua estreita relação com a experiência das idosas e em participar de Oficinas Socioculturais oferecidas pela UATI, voltadas para o conhecimento da história da cidade; a inserção comunitária e a discussão da cidadania, no sentido da participação, do engajamento e da organização na luta pela concretização de direitos que permitem o acesso a bens e serviços, quais sejam: Feira de Santana: uma viagem histórica e Cidadania do Idoso.

Em particular, destacamos o trabalho da Comissão de Núcleo de Bairro, composta por dezessete participantes, alunas da UATI, que iniciou suas atividades de estudo, após uma etapa inicial de planejamento em que foi assessorada pelo Núcleo de Estudos e Pesquisas da Terceira Idade (NEPTI) e participou de reuniões preparatórias com a Pró-Reitora de Extensão e Cultura (PROEC) e a Equipe Técnica da UATI a fim de estabelecer uma pauta comum de intenções visando à intervenção sociocultural no bairro Coronel José Pinto, tendo como horizonte a instituição de uma rede de sociabilidade mais ampla. Sabe-se que a exclusão social do idoso faz parte de um processo maior, denominado como paradigma da exclusão, relacionado a um quadro de ruptura dos laços sociais que atua em combinação com o enfraquecimento das formas de coesão e solidariedade habituais (MAGALHÃES, 2001).

Em um período da vida em que, geralmente, se está aposentado o idoso pode assumir a condição de um sujeito político, cuja ação visa agregar outros idosos em torno de um grupo de convivência integrado a um projeto de revalorização do bairro e dos espaços sociais existentes para a cultura e o lazer, a partir do debate de questões de interesse coletivo, visando à ação sociocultural no cotidiano. Espera-se que nesses espaços coletivos de convivência sejam fortalecidas as redes de sociabilidade e de solidariedade existentes, uma vez que está em jogo a participação de todos em torno de uma problemática comum.

2 Cidadania e Solidariedade: referências de intervenção sociocultural no bairro

Acreditamos que a experiência de participação na Comissão de Núcleo de Bairro constitui-se como uma estratégia ativadora das forças vivas 
das idosas, sendo assim, um espaço de mobilização social no qual se engendram novos modos de agir, outras possibilidades de interação e habilidades de luta para intervenção no bairro, caracterizado como territórioprocesso, no qual os idosos residem e mantêm vínculos familiares e de amizade. Para Magalhães (2001), trata-se de uma população fragilizada que apresenta maiores chances de ruptura dos vínculos profissionais, familiares e relacionais. Sabe-se que a família e o trabalho são os principais elos que garantem a inserção dos sujeitos nas diferentes redes de sociabilidade. No caso dos idosos, muitas vezes, tais ligações mostram-se frouxas, débeis e até mesmo esfaceladas, revelando a deterioração destas formas de convivência. Por tais razões, quem sabe, o envelhecimento é representado pelos idosos como algo, muitas vezes, assustador, sobretudo, pelo medo do isolamento, da potencial diminuição do status familiar e social e da conseqüente perda de oportunidades de participação social (AGUIAR; NASCIMENTO, 2005).

O território aqui referido ultrapassa sua limitação geográfica, abarcando a vida e suas relações no espaço local. Segundo Santos ${ }^{2}$ (1994, apud VILASBÔAS; MELO; $\operatorname{ALMEIDA}^{3}(1995$, p. 4) "[ . . . ] somente o espaço local pode produzir algum tipo de cidadania, de possibilidade de escolher a própria vida, e de regras que conduzem a sociedade."

Interessa-nos, especificamente, a idéia de que a Comissão pode constituir-se como agente coletivo de mudanças no bairro mediante a criação de uma rede solidária que reúna os moradores - trabalhadores e aposentados, donas de casa e estudantes, comerciantes e seus fregueses em torno de problemas de interesse comum, tendo como horizonte à constituição de um ethos solidário.

Solidariedade é um termo polissêmico que adquire sentidos variados em diferentes culturas. Tem sua origem no latim solidum, sólido, o que leva ao sentido de 'estar em bases sólidas', significa estar com outros na mesma situação, partilhar interesses comuns, identificar-se com o destino do outro. Desse modo, solidariedade implica uma relação de responsabilidade entre pessoas ligadas por interesses comuns, de forma que cada participante do grupo sinta a obrigação moral de apoiar o outro (STOTZ, 2003).

2 SANTOS, Milton. Só a Geografia Reconstrói. Folha de São Paulo, São Paulo, 5 set. 1994. Apud VILASBÔAS; MELO; ALMEIDA, 1995, p. 4.

3 VILASBÔAS, Ana Luiza; MELO, Cristina M, ALMEIDA, Lívia. A Territorialização em Saúde como Estratégia de Reorganização de Práticas Sanitárias na Secretaria Municipal de Saúde do Salvador/Bahia. Salvador; 1995, 24 p. Digitado. 
Estamos nos referindo a uma nova concepção de solidariedade na qual está em jogo a participação de todos os idosos na discussão, proposição de ações e intervenção em uma problemática comum (MAGALHÃES, 2001).

É interessante salientar, que nas visitas feitas aos domicílios a fim de identificar se nesses residem idosos, dá-se um encontro e criam-se possibilidades de debate de idéias. Acreditamos que a importância das visitas reside ainda, em permitir o resgate de laços de solidariedade, mediante o estabelecimento de camaradagem, a criação de uma nova rede de amizades e a descoberta de temas de interesse comum. Trata-se de uma concepção de solidariedade na qual está em jogo a participação dos idosos na luta em torno de problemáticas comuns.

Desse modo, as idosas visitadoras e os idosos visitados são os agentes das mudanças pretendidas no território, que constroem uma nova perspectiva de ações e interações sociais, movidos pelo desejo de inserção e pela possibilidade de encarnar o papel de atriz/ator social, às vezes, tão difícil em outros momentos de sua trajetória de vida.

Por isso o movimento das participantes da Comissão, à medida que adentra pelas avenidas, atravessa ruas, dobra esquinas e irrompe pelas casas, vai se consolidando como um processo de luta pelo reconhecimento de direitos sociais, de autonomia, de integração e de participação na sociedade feirense - um exercício de cidadania.

É o que reza o texto da Lei 8.842 de 04 de janeiro de 1994 no seu Art. $1^{\circ}$, ao estabelecer os princípios e diretrizes da Política Nacional do Idoso: "A política nacional do idoso tem por objetivo assegurar os direitos sociais do idoso, criando condições para promover sua autonomia, integração e participação efetiva na sociedade.” (BRASIL, 1997, p. 7). Também a Lei $10.741 \mathrm{de} 1^{\circ}$ de outubro de 2003, que institui o Estatuto do Idoso destinado a regular os direitos assegurados aos idosos reafirma que estes gozam dos direitos fundamentais inerentes à pessoa, que devem ser garantidos por todos os meios, visando à preservação de sua saúde e seu contínuo aperfeiçoamento moral, intelectual, espiritual e social, respeitando-se sua liberdade e dignidade (BRASIL, 2004).

Evidentemente a cidadania como um valor universal, ultrapassa a noção de direitos e só pode ser realizada numa sociedade como a nossa mediante a participação, o engajamento e a organização da sociedade civil (ASSIS; KANTROSKI; TAVARES, 1995). É na prática concreta que os direitos assegurados no texto das leis podem ser exercidos no contexto de vida. É, 
na tomada de posição de quem sente na pele o abandono da velhice, a falta de programas de reinserção social, de opções de lazer e, particularmente, o desvalor social do velho na sociedade que as participantes da Comissão, ao intervirem no bairro Coronel José Pinto constituem-se em sujeitos privilegiados, cujo saber de experiência capacita-os a movimentarem-se no território, tecendo uma rede solidária que se estende para além dos limites instituídos de ação da UATI.

\section{A Experiência da Comissão de Núcleo de Bairro, propriamente dita}

A ação das participantes da Comissão teve como meta inicial o levantamento sistemático de dados da situação de vida dos idosos do bairro Coronel José Pinto e suas imediações. A Comissão iniciou suas atividades em abril de 1999 selecionando, consultando fontes de pesquisa e discutindo temas pertinentes ao envelhecimento. Após isso, a Comissão visitou órgãos públicos federais, estaduais e municipais, empresas privadas como clínicas, farmácias, supermercados e bancos dos quais obteve patrocínio para aquisição de camisas, o que serviu como uma primeira forma de identificação das participantes. Por fim, participou de entrevistas em rádios, TV e jornais locais sociabilizando os resultados do levantamento com a comunidade local e da região.

O marco inicial das ações foi a visitação às residências a fim de verificar se havia morador idoso e quem era esse, com o objetivo de:

Conhecer a realidade do idoso no meio sociofamiliar, visando estender os conhecimentos adquiridos no Programa Universidade Aberta à Terceira Idade; Incentivar a formação de grupos de idosos, nos bairros, com vistas à sua reintegração ao convívio social e a prática consciente da cidadania. (UNIVERSIDADE ESTADUAL DE FEIRA DE SANTANA, 1999, p. 6).

O trabalho inicial da Comissão consistiu em fazer contatos, criando formas novas de aproximação com os idosos visitados e suas famílias, incentivando a participação nas reuniões e atividades culturais programadas e realizadas na sede da Associação de Ex-combatentes do Exército, mas 
acima de tudo, implicou na sensibilização dos idosos quanto ao desafio de reverter o isolamento social com os próprios corpos solidários. Segundo relataram-nos as participantes da Comissão, foi nesses momentos que puderam perceber o respeito das pessoas residentes no bairro em relação ao esforço desenvolvido. O que não foi pouca coisa, debaixo do sol de quase quarenta graus de Feira de Santana e contando com um precário sistema de transporte urbano para deslocar-se de um lado a outro.

$\mathrm{Na}$ verdade, $\mathrm{o}$ ato de visitar as residências, investigar a presença de idosos, comunicar-se com as pessoas visitadas, apresentando os objetivos da Comissão, exigiu das participantes a capacidade de lidar com as resistências e o preconceito por serem alunas da UATI ${ }^{4}$, além de habilidade na aplicação do formulário e no registro das informações. Segundo a Coordenadora da Comissão $0^{5}$ o conhecimento do cotidiano do bairro e das pessoas visitadas foi um elemento facilitador do processo, uma vez que todos os participantes residem ali.

A Comissão realizou o trabalho de campo no período de julho a setembro de 1999, mapeando o número de casas de cada rua do bairro, depois foi percorrendo as 39 ruas traçando o itinerário das 475 casas visitadas. A coleta de dados foi realizada com 603 idosos aplicando-se um formulário contendo questões acerca das seguintes variáveis: sexo, idade, estado civil, escolaridade, fonte de renda, tipo de moradia, condições de saúde, hábitos de lazer, relatos sobre a prática de exercícios e o interesse em participar das atividades promovidas pela Comissão no bairro, como palestras, passeios e reuniões.

Os dados obtidos permitiram traçar o seguinte perfil dos 603 idosos residentes no Bairro Coronel José Pinto. Foram identificados 410 (68\%) mulheres e 189 (31,3\%) homens, assim distribuídos: 187 (31\%) na faixa de 50-59 anos, 211 (35\%) de 60-69 anos, 120 (20\%) com 70-79 anos e 66 (11\%) com 80 ou mais anos. Quanto ao estado civil 354 (58,7\%) são casados, 157 são viúvos (26\%), 44 (7,3\%) são solteiros, 36 (6\%) são separados e 12 (2\%) são divorciados. No que diz respeito à escolaridade 231 (38,3\%) concluíram a $4^{\mathrm{a}}$ série do ensino fundamental, $54(9 \%)$ concluíram a $8^{\mathrm{a}}$ série do ensino fundamental, $61(10,1 \%)$ cursaram todo o ensino médio e oito $(1,3 \%)$ concluíram o ensino superior. Destaca-se, no entanto, o elevado número de analfabetos 244 (40,5\%), sendo que cinco idosos não responderam

${ }^{4}$ Consideradas 'pessoas de elite'.

${ }^{5}$ Em entrevista realizada por uma das autoras. 
$(0,8 \%)$. No que tange propriedade da residência, a maioria $528(87,6 \%)$ reside em casa própria e $75(12,4 \%)$ em casa alugada. Isso não significa que o idoso resida sozinho e ainda, que exerça o papel de provedor. A maioria dos idosos $526(87,2 \%)$ reside com familiares de diferentes graus de parentesco como cônjuges, filhos e netos, 28 (4,6\%) moram sozinhos, 28 $(4,6 \%)$ referiram que participavam de outros tipos de arranjos de moradia, sete $(1,7 \%)$ relataram que moravam com amigos e $15(2,5 \%)$ não responderam. Quanto à fonte de renda $375(62,2 \%)$ são aposentados, sendo que $228(37,8 \%)$ não possuem aposentadoria. Estes relataram que viviam de outros rendimentos ou recebiam auxílio financeiro de familiares. No que tange às condições de saúde foi relatada a ocorrência de doenças crônicodegenerativas como hipertensão arterial por 85 idosos (14\%), seguida de diabetes mellitus por $29(4,8 \%)$, osteoporose por $12(2 \%)$ e reumatismo por $19(3,1 \%)$. No que diz respeito à prática de atividade física foram citadas caminhadas $246(40,8 \%)$ e hidroginástica $23(3,8 \%)$. A atividade de lazer a mais comum foi assistir TV 159 (26,4\%), ir à igreja 184 (30,5\%), participar de reuniões com amigos $63(10,4 \%)$, passeios $56(9,3 \%)$, ir à praia $25(4,1 \%)$, realizar viagens $25(4,1 \%)$. Os idosos mostraram interesse em participar de atividades promovidas pela Comissão conforme relatado por 564 deles $(93,5 \%)$, sendo que somente três $(0,35 \%)$ responderam que não possuíam interesse e $36(6,0 \%)$ que não responderam.

Após a análise dos dados, as participantes da Comissão de Núcleo de Bairro fizeram uma discussão com os idosos visitados acerca dos principais problemas relatados, com destaque especial para a falta de espaços de convivência no bairro. A partir de uma dinâmica inicial de trabalho em que foram realizadas reuniões para o lançamento de propostas de ação no território, passaram à realização de palestras e atividades culturais como a apresentação de coral, dança, teatro, realização de oficinas de poesia e de artes durante o primeiro semestre de 2000. Conseqüente às gestões feitas pela Comissão, criou-se um clima favorável à constituição do GRUPO DE CONVIVÊNCIA VIVER FELIZ, que integra cerca de 40 idosos. As reuniões são realizadas uma vez por semana na sede da Associação de Ex-combatentes do Exército, as atividades culturais como comemoração do dia dos pais, dia das mães e festas religiosas são programadas com o apoio do NEPTI e realizadas em locais diversificados, bem como as atividades de lazer. Uma das participantes da Comissão que é aluna da UATI há mais tempo assumiu a Coordenação do Grupo. O grupo conta com a assessoria de uma professora 
que ministra a disciplina Saúde do Adulto e Idoso I no curso de Graduação em Enfermagem da UEFS e o apoio de outra idosa participante da Comissão que atua como secretária, preparando a pauta das reuniões, fazendo comunicados para os participantes e as atas das reuniões, entre outras demandas.

\section{Intervenção no Bairro Coronel José Pinto: perspectivas}

Podemos dizer que no bairro Coronel José Pinto vai sendo trilhado um caminho alternativo, que consiste na criação de estratégias de intervenção comunitária para além daquelas instituídas pelos poderes públicos, muitas vezes, incompetentes para dar conta da real construção de novos espaços sociais para a convivência dos idosos, possibilitando assim, o resgate da consciência social marcada pela: "[... ] vontade de viver, participar e assumir a sua presença no contexto social." (UNIVERSIDADE ESTADUAL DE FEIRA DE SANTANA, 1999, p. 2). Constitui-se assim, em um projeto de revalorização da vida no território, que integra a ação cidadã e solidária das alunas da UATI, também residentes no bairro Coronel José Pinto e demais idosos mapeados no levantamento.

Pensamos que o GRUPO DE CONVIVÊNCIA VIVER FELIZ passa a ser também uma instância de apoio social - de solidariedade e de luta contra a discriminação e o preconceito em torno do velho na nossa cultura - de exercício da cidadania.

É neste sentido, que se impõe mais uma vez o conceito de educação ao longo de toda a vida, concebida como uma construção permanente do sujeito, de seus interesses, habilidades e capacidade de tomar decisões. Neste caso, refere-se tanto ao desenvolvimento de novas competências no enfrentamento de problemas do cotidiano, quanto à construção de estratégias de luta por melhores condições de vida e à criação de novos laços sociais, na tessitura de uma rede de solidariedade que possibilita a descontrução de um cotidiano vazio e solitário - sem horizontes. À medida que os idosos tomam consciência de sua condição de excluídos, muitas vezes, e da necessidade de assumirem o compromisso social que lhes cabe como cidadãos partem para a prática concreta no território onde vivem, buscando levantar pautas sociais e culturais de ação solidária com base nas necessidades sentidas, assumindo a posição de protagonistas na defesa de sua dignidade e bem-estar, na 
perspectiva de uma vida mais plena, resgatando o significado social da cidadania.

As alunas da UATI mostram-se assim, aptas a utilizar-se de suas capacidades de tomar decisões, de agir cooperativamente mediante a partilha de saberes e o exercício da habilidade de negociação, visando à defesa de interesses comuns, ainda que, muitas vezes, conflitivos. Queremos crer que esta experiência concreta de mobilização e intervenção no tecido social do território poderá conduzir os moradores à realização de projetos comuns, possibilitando a re-significação do sentido da velhice para que o velho possa ser e se sentir cidadão ativo. Como diz GIUBILEI (1993, p. 11):

Para mim o idoso é aquele que vê no amanhã a continuidade do trabalho de hoje, aquele que não fica à espera de descanso, que vai à luta, que busca preencher os espaços da vida, que se vê como um elemento útil à sociedade. Enfim, aquele que acredita e demonstra que tem experiências a serem relatadas e que, acima de tudo, é ainda capaz de grandes realizações.

Para que o tempo de vida seja marcado pela esperança e não pela espera, tão comum entre idosos, pois ter esperança é “" [ . . ] ir atrás, é escavar, é procurar [... ]", é construir formas mais solidárias de convívio familiar e social (CORTELLA, 1998, p. 26).

THE EXPERIENCE OF THE NUCLEUS OF DISTRICT OF THE PROGRAM OPEN UNIVERSITY OF THE THIRD AGE OF THE STATE UNIVERSITY OF FEIRA DE SANTANA - BA: an exercise of citizenship and solidarity

\begin{abstract}
This is a report of an experience of socio-cultural intervention in Colonel José Pinto district in the city of Feira de Santana-Bahia, developed by seventeen students of the Program Open University to the Third Age of the State University of Feira de Santana (UATI/UEFS). It is an alternative
\end{abstract}


strategy of amplification of the actions of the UATI using the students potential as multipliers to make a systematic collection of data on the socio-economic and cultural profile of 603 seniors living in that district. The initiative under the guidance of the Nucleus of Studies and Research of the Third Age (NEPTI), has as it basic principle the concept of education as a lifetime process with the purpose of delineating social and cultural lists of soldary action that facilitate the ransom of the senior's social conscience in the struggle for the recognition of their social rights, autonomy and the capacity to participate in the life of society. It is therefore a project of revaluation of the district that integrates the solidary action of senior citizens that study in the UATI and those who live in that district.

Keywords: Third Age. Citizenship. Solidarity. Social Participation.

\section{REFERÊNCIAS}

AGUIAR, Maria Geralda Gomes; NASCIMENTO, Maria Ângela Alves do. Saúde, Doença e Envelhecimento: representações sociais de um grupo de idosos da Universidade Aberta à Terceira Idade (UATI) - Feira de SantanaBA. Textos Envelhecimento, Rio de Janeiro, v. 8, n. 3, 2005. Disponível em: <www. unati.uerj.br/tse/index.php>. Acesso em: 26 jun. 2006.

ASSIS, Marluce Maria A.; KANTROSKI, Luciane; TAVARES, José Lucimar. Participação Social: um espaço em construção para a conquista da cidadania. Revista Brasileira de Enfermagem, Rio de Janeiro, v. 48, n. 4, p. 329-340, out./dez. 1995.

BRASIL. Ministério da Previdência e Assistência Social. Lei n ${ }^{\circ} 8.842$, de 4 de janeiro de 1994. Dispõe sobre a Política Nacional do Idoso. Brasília: Ministério da Previdência e Assistência Social. Secretaria de Assistência Social, 1997.

BRASIL. Lei ${ }^{\circ} 10.741$ de $1^{\circ}$ de outubro de 2003. Dispõe sobre o Estatuto do Idoso. Brasília: Senado Federal, Subsecretaria de Edições Técnicas, 2004.

CORTELLA, Mário Sérgio. Repensando o Envelhecer: entre o mito e a razão. A Terceira Idade, São Paulo, v. 10, n. 13, p. 7-28, abr. 1998. 
DAMASCENO, Maria Nobre. A Formação de Novos Pesquisadores: a investigação como uma construção coletiva a partir da relação teoria-prática. In: CALAZANS, Julieta. Iniciação Cientifica: construindo o pensamento crítico. São Paulo: Cortez, 1999. P. 13-55.

DELORS, Jacques. A Educação ou a Utopia Necessária. In:

Educação: um tesouro a descobrir. Tradução José Carlos Eufrázio. 2. ed. São Paulo: Cortez; Brasília: MEC, UNESCO, 1999. P. 11-32.

GIUBILEI, Sonia. Uma Pedagogia para o Idoso. A Terceira Idade, São Paulo, v. 5, n. 7, p. 10-14, jun. 1993.

MAGALHÃES, Rosana. Integração, Exclusão e Solidariedade no Debate Contemporâneo sobre as Políticas Sociais. Cadernos de Saúde Pública, Rio de Janeiro, v. 17, n. 3, p. 569-579, maio/jun. 2001.

STOTZ, Eduardo Navarro. Ações de Solidariedade na Saúde: semântica, política e ideologia diante da pobreza e da doença. In: GOOLDENBERG, Paulete; MARSIGLIA, Regina Maria Giffoni; GOMES, Maria Helena de Andréa. O Clássico e o Novo: tendências, objetos e abordagens em ciências sociais e saúde. Rio de Janeiro: Fiocruz, 2003. P. 349-361.

UNIVERSIDADE ESTADUAL DE FEIRA DE SANTANA. Pró-Reitoria de Extensão e Cultura. Programa Universidade Aberta à Terceira Idade. Sintese da Proposta de Trabalho. Feira de Santana, 1999. 